\title{
Stereotactic radiotherapy for early stage non-small cell lung cancer: current standards and ongoing research
}

\author{
Eugenia Vlaskou Badra, Michael Baumgartl, Silvia Fabiano, Aurélien Jongen, Matthias Guckenberger \\ Department of Radiation Oncology, University Hospital Zurich, University of Zurich, Zurich, Switzerland \\ Contributions: (I) Conception and design: M Guckenberger, E Vlaskou Badra; (II) Administrative Support: M Guckenberger, E Vlaskou Badra; \\ (III) Provision of study materials or patients: None; (IV) Collection and assembly of data: All authors; (V) Data analysis and interpretation: M \\ Guckenberger, E Vlaskou Badra; (VI) Manuscript writing: All authors; (VII) Final approval of manuscript: All authors. \\ Correspondence to: Matthias Guckenberger. Department of Radiation Oncology, University Hospital Zurich, University of Zurich, Switzerland, \\ Raemistrasse 100, 8091 Zurich, Switzerland. Email: matthias.guckenberger@usz.ch.
}

\begin{abstract}
Stereotactic body radiation therapy (SBRT) allows for the non-invasive and precise delivery of ablative radiation dose. The use and availability of SBRT has increased rapidly over the past decades. SBRT has been proven to be a safe, effective and efficient treatment for early stage non-small cell lung cancer (NSCLC) and is presently considered the standard of care in the treatment of medically or functionally inoperable patients. Evidence from prospective randomized trials on the optimal treatment of patients deemed medically operable remains owing, as three trials comparing SBRT to surgery in this cohort were terminated prematurely due to poor accrual. Yet, SBRT in early stage NSCLC is associated with favorable toxicity profiles and excellent rates of local control, prompting discussion in regard of the treatment of medically operable patients, where the standard of care currently remains surgical resection. Although local control in early stage NSCLC after SBRT is high, distant failure remains an issue, prompting research interest to the combination of SBRT and systemic treatment. Evolving advances in SBRT technology further facilitate the safe treatment of patients with medically or anatomically challenging situations. In this review article, we discuss international guidelines and the current standard of care, ongoing clinical challenges and future directions from the clinical and technical point of view.
\end{abstract}

Keywords: Stereotactic body radiation therapy (SBRT); stereotactic ablative radiotherapy (SABR); non-small cell lung cancer (NSCLC); lung cancer; early stage

Submitted Jul 15, 2020. Accepted for publication Oct 19, 2020.

doi: $10.21037 /$ tlcr-20-860

View this article at: http://dx.doi.org/10.21037/tlcr-20-860

\section{Current standard of SBRT for early-stage NSCLC}

Epidemiology, bistory, and development of SBRT as standard of care

Lung cancer is among the most frequent malignancies and the leading cause of cancer-related deaths worldwide (1), with non-small cell lung cancer (NSCLC) accounting for approximately $5 \%$ of all cancer-related mortality. Around $16 \%$ of patients with NSCLC are diagnosed at early stages, which are characterized by a small primary tumor and lack of lymph node metastases (stages T1-2, N0) (2). This proportion of early stage NSCLC is expected to increase in health care systems with implementation of CT-based lung cancer screening $(3,4)$.

Early-stage (ES) NSCLC has traditionally been managed by lobectomy and systematic hilar and mediastinal lymph node dissection. An overall survival of $60-92 \%$ at 5 years (5) indicates this tumor stage as a curable disease. A significant number of patients is however medically inoperable due to their comorbidities and this proportion of inoperable or high-risk patients is growing due to an aging population (6). For this group of patients, traditional treatment options have been best supportive care, limited/extra-anatomical resection, and 
radiotherapy. Conventionally fractionated external beam radiotherapy (EBRT) with total irradiation doses of 6066 Gy had been an established curative treatment option for such medically inoperable patients. However, several studies reported a dose-response relationship for radiation doses beyond this range, with improved local tumor control and survival for higher radiation doses (7).

Stereotactic body radiation therapy (SBRT) is defined as a form of EBRT that accurately delivers a high dose of radiation to an extracranial target in a single or few fraction(s) (8). Developed in the early 1990s (9), SBRT was further adapted and advanced by multiple groups and is nowadays a wellestablished and guideline-recommended component of modern radiotherapy. In some publications, SBRT is referred to as stereotactic ablative radiation therapy (SABR).

Multiple, methodologically and technically diverse studies on SBRT in early-stage NSCLC have consistently shown favorable outcomes in terms of high local control rates $(74-100 \%)$, preserved quality of life, and low treatment-related toxicity (10-21). Recent randomized clinical trials (RCTs) comparing EBRT and SBRT have shown comparable results in terms of progression-free (PFS) $(17,20)$ and improved overall survival (OS) (20) in favor of SBRT. Today, SBRT is established as the gold standard for medically inoperable patients with ES NSCLC (22-27), with increasing use, due to aging populations in many societies. Figure 1 illustrates an exmple of ES NSCLC treated at our institution.

\section{Guideline perspective of SBRT for ES NSCLC}

\section{Clinical practice guidelines}

International guidelines $(22-24,27)$ recommend treating node-negative ES NSCLC with surgical lobectomy, if pulmonary and cardiac comorbidities allow it. In patients considered medically inoperable based on an interdisciplinary discussion, as well as in those unwilling to undergo surgery, SBRT is the treatment of choice. The European Society for Radiotherapy and Oncology (ESTRO) Advisory Committee in Radiation Oncology Practice (ACROP) consensus guidelines also suggest a minimum performance status of ECOG 3 and a minimal estimated life expectancy of one year for SBRT patient selection (24).

For assessment of patient operability, guidelines agree on a multidisciplinary patient assessment. Pre-treatment evaluation before SBRT or surgery includes (but is not limited to) pulmonary function testing, bronchoscopy, mediastinal lymph node evaluation, PET/CT staging

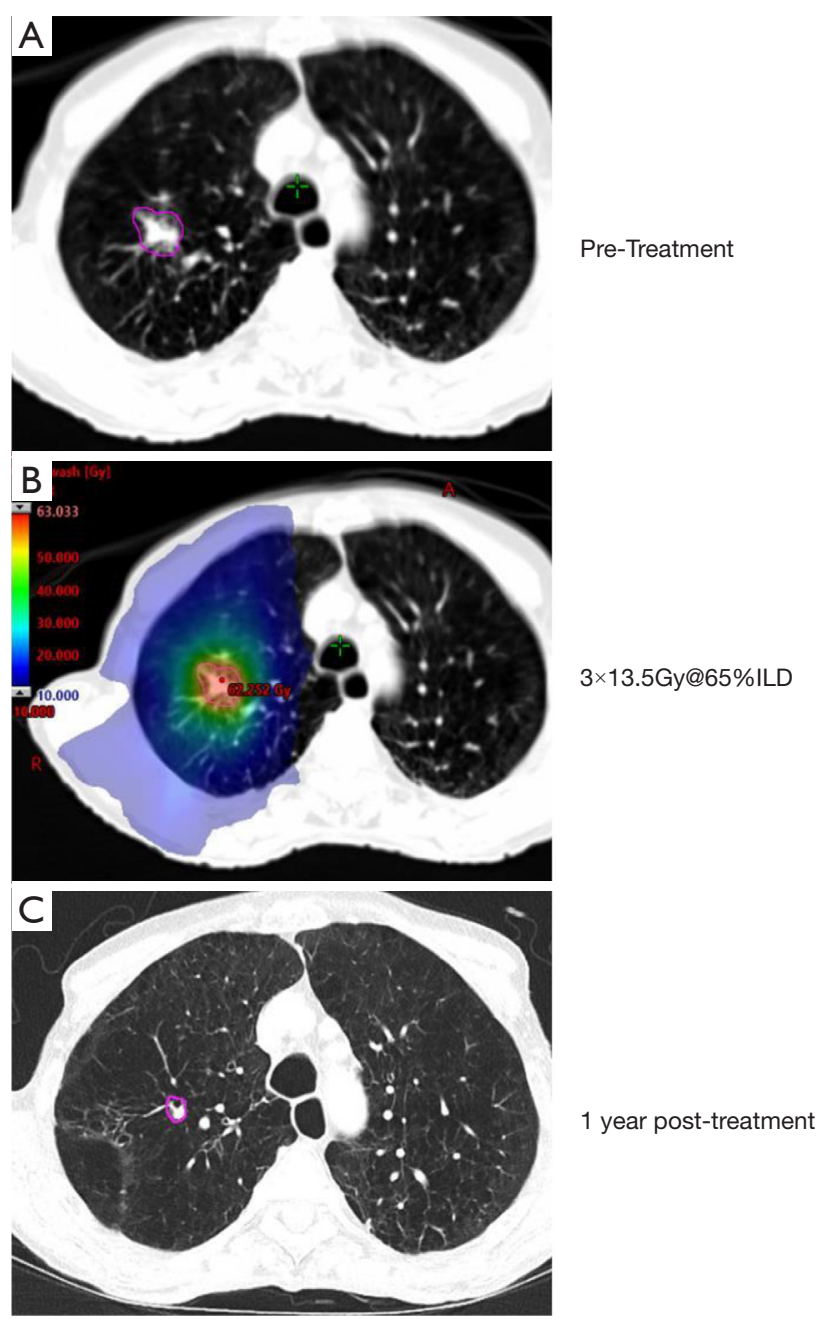

Figure 1 Patient case. Figure shows a patient treated at our institution with 3×13.5 Gy@65\% ILD. (A) Pre-treatment; (B) treatment plan; (C) 1 year post-treatment.

(22-25) while some also recommend cranial MRI in stages IB (optional) to IIA (23). While SBRT is the treatment of choice in inoperable patients according to the abovementioned guidelines, there is no commonly accepted definition of patient inoperability. The perioperative risk can be estimated using validated systems especially considering cardio-pulmonary function-however, none have yet been prospectively validated in NSCLC patients.

Pre-SBRT biopsy confirmation is strongly recommended but not a prerequisite for patients unwilling to undergo invasive biopsy or patients with an excessively high periprocedural risk (23-25). The challenge of clinically diagnosed ES NSCLC will be discussed later in this article.

The main failure pattern after treatment of ES NSCLC 
is distant, with about $20-30 \%(28,29)$ of the patients developing metastatic disease during follow-up. Some guidelines, therefore, recommend the evaluation of adjuvant chemotherapy after SBRT in patients with highrisk features, such as poor tumor differentiation, vascular invasion, pleural involvement, and unknown lymph node status (25) while others do not (23).

Follow-up after SBRT should consist of clinical visits and CT imaging every 3-6 months for at least two years. Distinguishing between post-therapeutic fibrosis and persistent or recurrent NSCLC is as pivotal as complex. For CT-based follow-up imaging, high-risk features, such as bulging margin, craniocaudal extension, and linear margin disappearance have been identified to more accurately differentiate between vital tumor and progressive fibrosis $(30,31)$. FDG-PET/CT scans are not routinely recommended but should be used in patients where differentiation between post-SBRT fibrosis and tumor recurrence is otherwise difficult $(23,24,32)$.

Guidelines do not routinely endorse SBRT as primary treatment in patients deemed to be at a "standard operablerisk", despite concerns regarding surgical mortality and morbidity. Literature has demonstrated 3 year-OS rates of $76-86 \%(15,32-36)$ after SBRT in selected cohorts of operable patients unwilling to undergo surgery. A metaanalysis of 4850 patients within 40 SBRT studies and 7,071 patients within 23 surgical studies in ES NSCLC reported no significant difference in OS or disease-free survival (DFS) when adjusting for age and comorbidities (37). Another metaanalysis of 23 studies reported improved outcome in terms of overall- and cancer-free-survival after surgery compared to SBRT in both the matched and unmatched group (38). All retrospective and cross-study comparisons suffer from insufficient matching of surgical and SBRT patient cohorts because relevant prognostic factors are frequently unavailable for the matching process. Additionally, such studies have been shown to be prone to interpretation bias (39). Randomized prospective trials are therefore needed to properly address this important clinical question.

\section{Medical physics practice guidelines}

In order to describe the technical requirements of treatment units for safe and effective SBRT of ES NSCLC, six national and international guidelines, recommendations, and an expert review group consensus were reviewed $(22,24,40-42)$.

The ESTRO ACROP consensus has been released with the key aspects on SBRT treatment delivery for
ES NSCLC, discussing in detail the minimum machine performance (22). The ASTRO guideline provides a detailed overview about the clinical part only (24) whereas the listed American Association of Physicists in Medicine (AAPM) reports cover the technical requirements for SRS/ SBRT in general (22,24,40-43). The Deutsche Gesellschaft für Medizinische Physik (DGMP) expert review gives a fair overview of technical specifications necessary for SBRT/ SRS treatments in general (42).

There is a strong agreement in implementing an endto-end test during the commissioning phase of the linear accelerator, not only to check the accuracy and reliability of the system before a first SBRT treatment, but also to conduct regular machine quality assurance (QA) checks to guarantee a stable performance of the treatment unit afterwards. End-to-end tests are powerful tools in QA protocols to ensure the reliability of the entire treatment chain through sufficient imaging protocols for the planning CT, image reconstruction, data transfer, treatment planning system performance, motion management, and irradiation of dummy treatment plans on QA phantoms and comparing calculated with measured data. Most importantly, the equipment specific QA has to be extended and pass stricter criteria than standard IMRT QA protocols (43).

Teaching of the medical staff involved in SBRT treatment, continuous training, credentialing, setting up standard operating procedures and clinical protocols are all essential and indispensable to be conducted and implemented before and while providing SBRT treatments in general $(22,24,40-44)$.

Despite the fact that dedicated SBRT treatment devices such as the CyberKnife ${ }^{\circledR}$ or Vero ${ }^{\circledR}$ are compelling and well established technologies in radiation therapy, their added value in comparison to standard linear accelerators (linacs) is uncertain (22). For most of the radiation oncology centers, standard linacs represent the most accessible, affordable, and efficient treatment units. Most modern machines are equipped with necessary SBRT quality requirements: high-resolution multi-leaf collimators (MLC) $<10 \mathrm{~mm}$, volumetric image-guided radiation therapy (IGRT) technology, and 4D-CT. They can therefore be used for standard and more sophisticated treatment techniques such as SBRT for ES NSCLC (22).

\section{Current challenges in SBRT for ES NSCLC}

Patients with centrally/ultra-centrally located NSCLC SBRT in ES NSCLC is a well-tolerated and efficient 
treatment with high rates of local control when applied to peripherally located lesions. However, as high ablative doses are needed in order to achieve optimal tumor control, SBRT in tumors located close to critical structures (such as major bronchi, esophagus, large vessels, and brachial plexus) is potentially associated with a higher risk of organs at risk (OAR) damage. Although commonly used in literature as well as in clinical practice, there is no uniformly accepted definition of the terms "central" or "ultracentral".

Timmerman et al. initially reported "excessive toxicity" in patients with central tumors treated with 3 fractions of 20-23 Gy. Tumor location was the strongest predictive factor for toxicity, with up to 11 -fold increased risk of grade 3 or higher toxicities (45). Those results led to the development of the first "no-fly" zone definition, adapted by the RTOG 0236 trial and still in use by the ASTRO guideline (24), which defined central tumor location as " $2 \mathrm{~cm}$ in all directions around the proximal bronchial tree (PBT)" (45).

The RTOG 0813 trial tumors (46) was designed to evaluate SBRT outcomes in centrally located NSCLC and added to the RTOG 0236 definition as follows "the zone [...] of RTOG 0236, with the addition of tumors which are immediately adjacent to mediastinal or pericardial pleura (PTV touching the pleura)" (46). The International Association for the Study of Lung Cancer (IASLC) has a broader definition for central tumor location "within $2 \mathrm{~cm}$ in all directions of any mediastinal critical structure, including the bronchial tree, esophagus, heart, brachial plexus, major vessels, spinal cord, phrenic nerve, and recurrent laryngeal nerve" (32). While patients with centrally located ES NSCLC are at a higher risk of toxicity from SBRT, surgery in this population is also associated with worse outcomes (47).

The term "ultracentral" has been established more recently and is also lacking a uniform definition. It often refers to tumors directly abutting or invading the PBT or esophagus (24). All definitions have in common that anatomical location and not radiotherapy doses to critical organs at risk are the basis for risk stratification.

A 2013 systematic review (48) analyzed findings of 20 trials, including 315 ES NSCLC tumors out of a total of 563 centrally located lung tumors. They reported SBRTrelated mortality of $2.7 \%$ and grade 3 or higher toxicities at $9 \%$. The OS did not differ between central and peripheral tumors, but the heterogeneity of treatment delivery did not allow the determination of an optimal dose/fractionation regime. Since then, several single-center-studies have been published, mostly $(12,32,49-51)$, but not exclusively $(52,53)$, reporting central tumor location as a predictor for increased toxicity.

The RTOG 0813 trial-a seamless phase I/II trialevaluated fractionation schedules of 5 fractions every two to three days up to a total dose ranging from 50-60 Gy, escalating in 0.5 Gy per fraction steps. With a median follow-up of 37.9 months, they reported a maximal tolerated dose of $5 \times 12.0 \mathrm{~Gy} / \mathrm{fx}$, with an accompanying probability of $7.2 \%$ dose-limiting toxicity. Local control at 2 years in the $11.5 \mathrm{~Gy} / \mathrm{fx}$ and $12.0 \mathrm{~Gy} / \mathrm{fx}_{\mathrm{x}}$ cohorts was $89.4 \%$ and $87.9 \%$, respectively, while OS was reported at $67.9 \%$ and $72.7 \%$ and therefore comparable to outcomes of peripheral tumors (46). However, there were relevant numbers of adverse events with a total of 13 out of 70 patients (19\%) experiencing toxicity graded 3 and higher, while grade 5 toxicity was reported for 6 patients.

The treatment of central NSCLC in inoperable patients or those unwilling to undergo surgery has been evaluated prospectively within the multicentric EORTC LungTech trial (54,55). Endpoints include treatment efficiency and toxicity. They defined central tumor location as "located within $2 \mathrm{~cm}$ or touching the zone of the proximal bronchial tree or immediately adjacent to the mediastinal or pericardial pleura, with a PTV expected to touch or include the pleura" (54). The study closed early due to slow recruitment: Two potentially treatment related deaths were observed after inclusion of 39 patients.

The Nordic HILUS trial, a phase-II-multicenter trial on SBRT to central tumors, included primary NSCLC as well as metastatic disease. They defined central location as tumors located within " $\leq 1 \mathrm{~cm}$ from the proximal bronchial tree". Forty-two out of 74 patients had tumors located close to the main bronchus (arm A) while 31 patients had tumors located close to a lobar bronchus (arm B). Toxicity graded 3 or higher was reported in $28 \%$ of patients, while $9 \%$ (a total of seven patients, six patients in arm A and one patient in arm B) experienced grade 5 toxicity (lethal hemoptysis and pneumonitis) $(12,21)$.

Recent data on ultracentral tumors show comparable rates of local control, but with sometimes substantial toxicity rates (56-58). While the possibility of potentially fatal toxicity in high-risk cohorts remains present, literature reports reasonable outcomes, particularly with protracted fractionation schedules. International guidelines therefore recommend SBRT in patients with central ES NSCLC using risk-adapted fractionation regimes $(22,24)$, however an optimal fractionation schedule has not been recommended. An ongoing multicentric phase I dose 


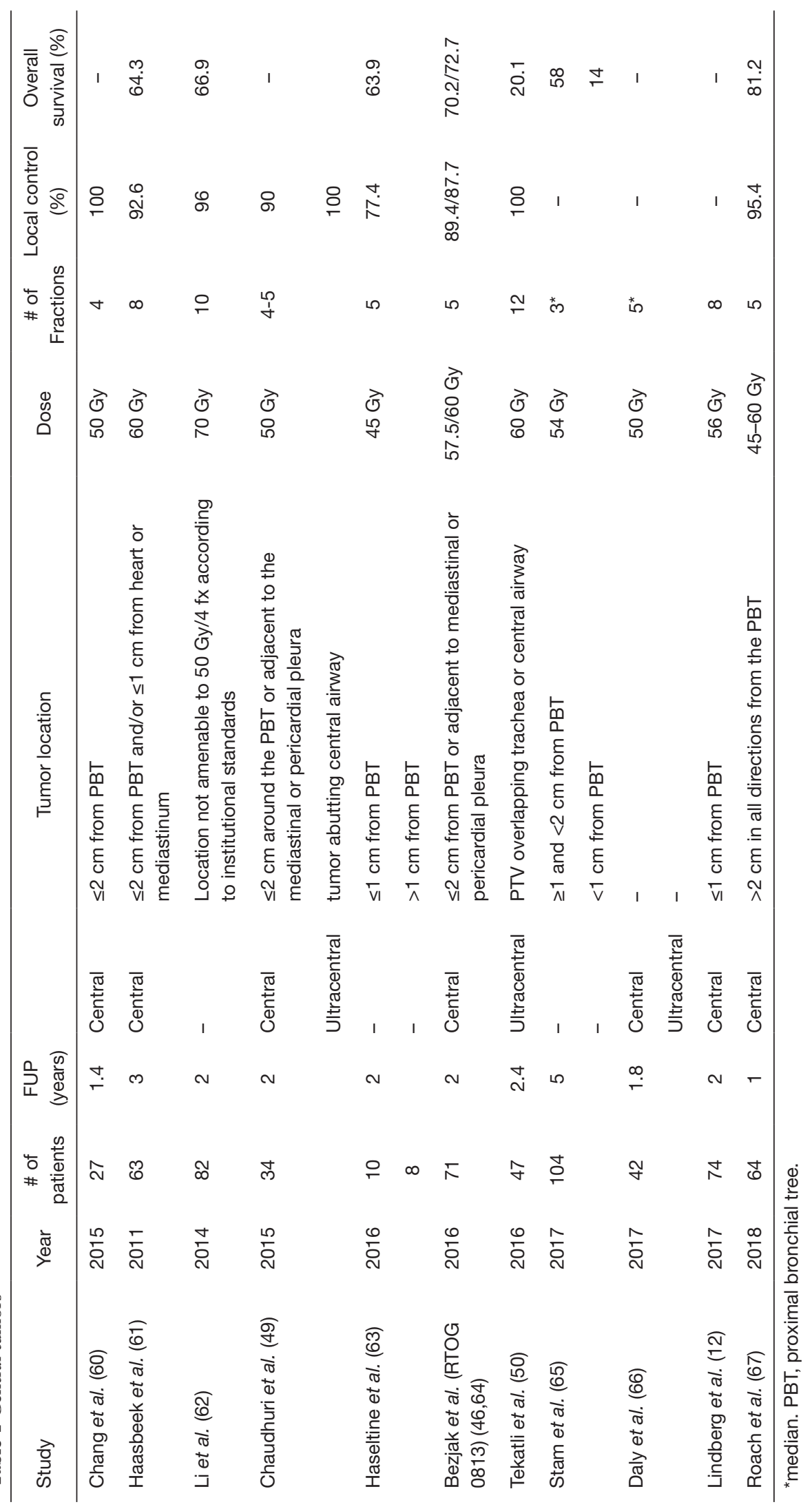



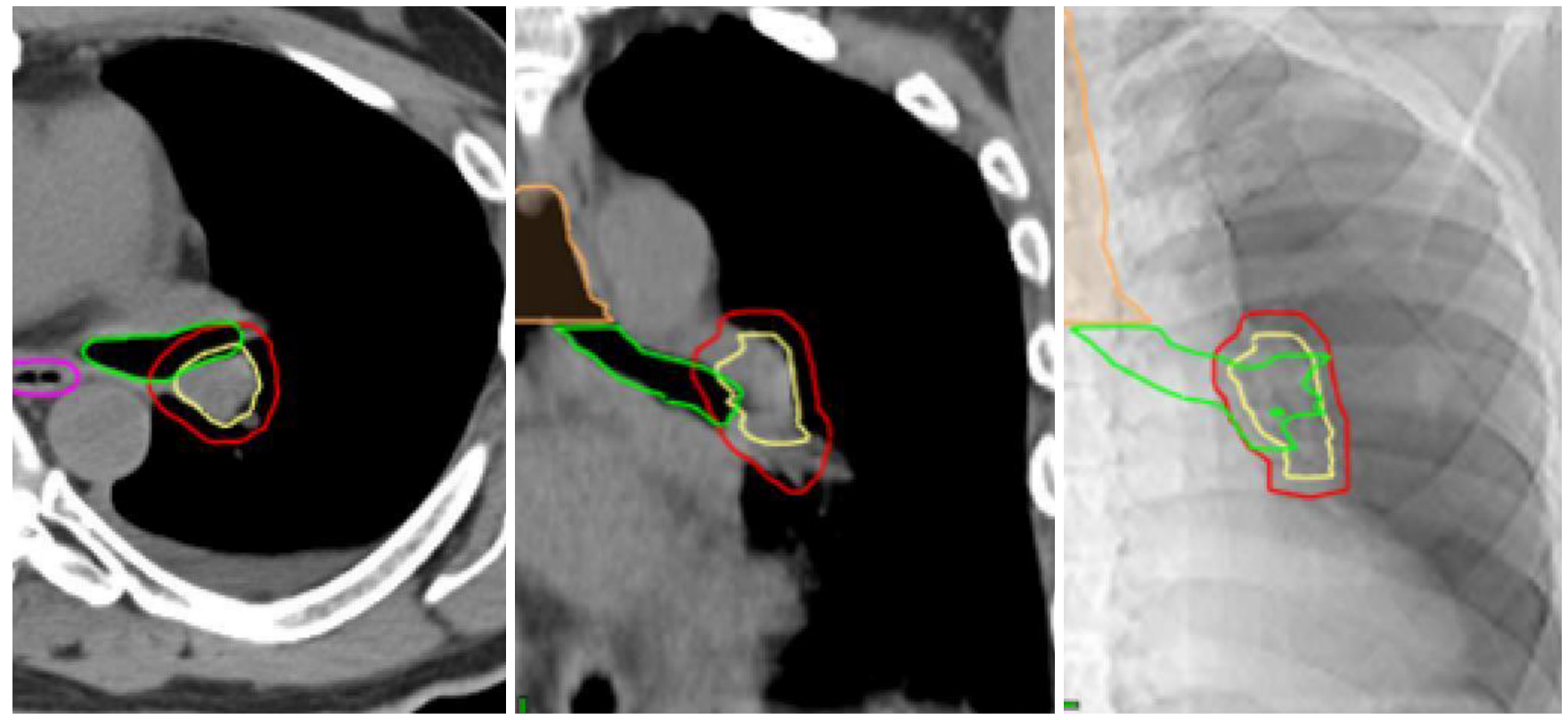

Figure 2 Centrally located NSCLC. Color Coding: pink = esophagus, orange = trachea, green = main bronchus, yellow = internal target volume (ITV), red = planning target volume (PTV).

escalation study, the SUNSET trial, is currently evaluating maximal tolerated dose in this setting in order to identify a safe and efficient fractionation regime, starting out at $60 \mathrm{~Gy}$ in 8 daily fractions (59) (Table 1, Figure 2).

\section{Patients without histopathological confirmation of cancer}

Obtaining histologic confirmation of solid pulmonary nodules or masses by biopsy is highly recommended in all practice guidelines $(22-25,68)$. However, a relevant proportion of patients has been undergoing SBRT without biopsy confirmation (55). This is in patients considered as being at a too high-risk for performing trans-thoracic or trans-bronchial biopsy confirmation. The probability of malignancy is then estimated using clinical scores considering clinical and imaging factors such as smoking status, lesion size and growth rate, CT morphological criteria such as spiculae, and FDG- PET activity (69).

Retrospective data on clinically-diagnosed ES NSCLC lesions treated with SBRT, as opposed to histologicallyproven ones, showed no significant difference regarding OS and local control while similar rates of DFS and distant failure between pathologically confirmed and presumed NSCLC (70-74) were observed.

A recent prospective observational study of 62 patients undergoing SBRT without histologic confirmation of malignancy (median follow-up of 55 months) reported a 3 -year OS of $83.3 \%$ for all patients and $94.7 \%$ for those under the age of 74. Local, locoregional, and distant failure was reported at rates of $6.4 \%, 4.8 \%$, and $11.7 \%$, respectively. Eight patients experienced toxicity graded 3 and 4 , and there were no grade 5 toxicities (75).

A systematic review and meta-analysis of 11,047 patients treated with SBRT in 47 cohorts showed a more favorable outcome in terms of DFS and cause-specific survival in clinically staged patients compared to biopsy-proven ones. Regarding OS, they showed better outcomes for the clinically staged patients at 3 years, however 5 -year OS did not differ significantly (76).

It is important to note that the treatment of lung lesions without prior histological confirmation, whether with SBRT or surgery, represents a risk of overtreatment of benign lesions. In patients ineligible for, or refusing biopsy, SBRT is a guideline-recommended option for suspected malignancies (22-25,68).

\section{Patients with coexisting interstitial lung disease}

Interstitial lung diseases (ILDs) are a heterogeneous group of diffuse parenchymal lung disorders with various patterns of inflammation and extents of fibrosis $(77,78)$. Idiopathic pulmonary fibrosis (IPF) is the most common form of ILD and describes a chronic and progressive condition of 
fibrosing of lung tissue, with a median survival of 2-3 years $(77,78)$. IPF has a poor outcome by itself, but it is also associated with increased rates of lung cancer (79) and treatment-related toxicity $(80)$ or ineligibility for treatment.

Although normo-fractionated radiotherapy of either curative or palliative intent in patients with (sub)clinical ILD has traditionally been associated with a relevant risk of severe radiation-induced pneumonitis (81-83), retrospective studies on the SBRT have shown mixed results.

While some studies evaluated SBRT in ES NSCLC alone $(84,85)$, others evaluated ES NSCLC and metastatic lung disease alike $(83,86)$. All except for one (87) reported significantly higher rates of radiation pneumonitis in their ILD cohorts, with reported incidence of underlying ILD of $6-16 \%$ of patients $(84-86,88)$. The incidence of radiation pneumonitis graded $\geq 2$ and $\geq 3$ in ILD patients was reported at significantly higher rates of $19-55 \%$ and $10-32 \%$, respectively in all (84-86) but one (87) study. Grade 5 radiation pneumonitis was reported at rates of 7.6-20\% $(85,86)$. Therefore, the risk of severe toxicity and mortality after SBRT for ES NSCLC needs to be carefully balanced with the risk of the underlying cancer and the pulmonary diseases.

\section{Patients with local recurrence after initial SBRT}

Management of local recurrence after SBRT is limited by thorough patient selection. Surgical resection is barely an option in medically inoperable patients, but presents as a salvage treatment option in those previously unwilling to undergo surgery (89-91). Evidence on repeat SBRT after initial SBRT is limited in terms of patient volume and its retrospective nature. The largest cohort to date has been reported by Ogawa et al. (92), consisting of 31 patients $(\mathrm{n}=23$ with NSCLC; $\mathrm{n}=8$ with lung metastasis) with either radiologically $(\mathrm{n}=17)$ and histologically $(\mathrm{n}=14)$ proven local recurrence after initial SBRT. The initial SBRT treatments were mainly performed with 48-52 Gy in 4 fractions, while repeat SBRT doses were mainly either the same or $60 \mathrm{~Gy}$ in 8 fractions. The reported OS, PFS and local control at three years for NSCLC patients was $27 \%, 40 \%$, and $40 \%$, respectively, for central location and $31 \%, 25 \%$, and $52 \%$, respectively, for peripheral location, with no toxicity graded 3 or higher reported (84). Smaller studies have reported comparable results (93-99). The available data suggests that salvage SBRT with BED $>100 \mathrm{~Gy}_{10}$ appears to be well tolerated and safely applicable in carefully selected patients with peripheral tumor location; repeat SBRT should be evaluated only very carefully in centrally located tumors (95).
However, as grade 5 toxicity $(95,97,100)$ has been reported in this setting and due to the limited availability of data, more studies evaluating fractionation and dose constraints and normal tissue tolerance are warranted.

\section{Research perspective of SBRT for ES NSCLC}

\section{Clinically oriented research}

\section{SBRT as neoadjuvant/adjuvant treatment to surgery in operable patients}

SBRT in NSCLC is most commonly used as a single modality treatment. While many studies aimed to improve R0 resection rates in locally advanced NSCLC (101), such concepts are at a very early stage for ES NSCLC. The MISSILE-NSCLC trial was the first prospective phase II trial, which aimed to evaluate complete pathologic response (pCR) after neoadjuvant SBRT in ES NSCLC (101). They reported a pCR rate of $60 \%$ at ten weeks after SBRT, a local control rate of $100 \%$ at two years, and unchanged QoL, while treatment-related toxicity was comparable to that of surgery alone (102). The pCR rate appears low compared to local control rates after SBRT and has been critically discussed. However, it needs to be considered that definition of pCR shortly after high-dose is not well defined and pCR is well known to increase after follow-up longer than $2-3$ months.

\section{SBRT instead of surgery in operable patients}

Promising outcomes in inoperable ES NSCLC have prompted attempts to implement SBRT in the management of medically operable, fit patients. To date, there are no published RCT comparing SBRT vs. lobectomy (VATS) in medically operable stage I NSCLC patients. Three prospective trials comparing SBRT with surgery (STARS, ROSEL and Z4099) $(32,103)$ were terminated early due to poor accrual, while a feasibility study in the United Kingdom showed that a large RCT is not feasible owing to the same reason (104). The pooled-analysis of the STARS and ROSEL trials however-while limited-reported promising results and an advantage of $15 \%$ in OS with SBRT (60), while two prospective trials (JCOG0403 and RTOG 0618) reported high rates of tumor control and low treatment-related morbidity $(34,35)$. While retrospective data suggests likely equal or superior outcomes with surgery, more randomized trials comparing surgical approaches to SBRT in the medically operable are warranted. The ongoing POSITIVL (105), VALOR (106) and STABLE- 
MATES (107) trials aim to evaluate SBRT vs. complete resection (not further specified), lobectomy, and sublobar resection respectively in medically operable patients within a randomized control trial.

\section{SBRT combined with cytotoxic chemotherapy}

Although SBRT can achieve excellent local tumor control, overall survival is predominantly limited by regional and distant disease progression after SBRT for ES NSCLC. Robinson et al. reported 4-year local, regional, and distant control after SBRT of $93.6 \%, 78.1 \%$, and $54 \%$, respectively (108). This forms the rationale for investigating the combination of systemic treatment with SBRT, aiming to improve OS.

To date, no randomized prospective studies have examined the addition of chemotherapy before or after SBRT for ES NSCLC.

A retrospective analysis of the National Cancer Database showed that only $3 \%$ of analyzed patients received adjuvant chemotherapy after SBRT between 2004 and 2014 (109). Those patients had a significantly worse OS as compared to patients receiving SBRT only (28.0 vs. 36.5 months, $\mathrm{P}=0.001)$. After propensity-score matching, this difference increased further (28.0 vs. 47.7 months, $\mathrm{P}<0.0001)$. For the subset of patients with tumors greater than $4 \mathrm{~cm}$, no statistically significant difference in OS was found, even after propensity-score matching. Whether this surprising difference is the result of the different treatment protocols or of different patient and disease characteristics, which were not corrected in the propensity-score matching, remains unknown.

These results are in disagreement with the retrospective study of Chen et al., which showed an improved OS for patients receiving cisplatin-based adjuvant chemotherapy as opposed to those receiving SBRT alone (47 vs. 36 months, $\mathrm{P}=0.035)$ (110). It is however important to note that patients were not randomized and that those who did not receive chemotherapy were either considered too old (over 75 years of age) or had relevant comorbidities. It is therefore likely that the two populations were heterogeneous, which could explain the lower overall survival in the SBRT-only group.

Verma et al. also analyzed the National Cancer Database, focusing exclusively on tumors greater than $5 \mathrm{~cm}$ treated $<10$ SBRT fractions (88). When comparing patients receiving chemotherapy (before or after SBRT) to those receiving SBRT solely, OS was significantly greater in the former group (30.6 vs. 23.4 months, $\mathrm{P}=0.027)$. The role of chemotherapy remained significant in multivariate analysis (111). Those results suggest that adjuvant chemotherapy after SBRT for ES NSCLC may be beneficial, mainly in patients with larger tumors. Prospective data are needed to verify this hypothesis.

\section{SBRT combined with immune checkpoint inhibition}

In advanced-stage NSCLC, immunotherapy alone or in combination with chemotherapy has achieved significant and clinically relevant overall survival improvements in comparison with chemotherapy for patients with both squamous and non-squamous advanced NSCLC $(111,112)$. Despite this background from metastatic NSCL and a strong preclinical rational, there are currently no published studies combining SBRT with immunotherapy in ES NSCLC.

An abstract from Daly et al. was published in October 2019 , reporting the results of a phase I study that included 15 patients receiving Atezolizumab, a PD-L1 inhibitor, and SBRT (50 Gy in four or five fractions). Patients received intravenous Atezolizumab every 21 days over six cycles, while SBRT was delivered concurrently at the beginning of the third cycle (113). The dose-limiting toxicity was assessed for 12 patients and the combination was well tolerated, with no grade 4 or 5 events and only one grade 3 event requiring interruption of treatment.

Several randomized phase III clinical trials are currently ongoing. Amongst them, the PACIFIC-4 trial (NCT03833154) aims to recruit 706 stage I or II (with negative lymph nodes) patients by 2025 (114). This double-blind, multi-center trial will investigate the benefit in progression-free survival when adding monthly Durvalumab (PD-L1 inhibitor) versus placebo for 2 years following SBRT. Another phase III study (NCT04214262) was started this year to study the influence of Atezolizumab (another PD-L1 inhibitor) on OS, when administered before and after SBRT (115) (NCT04214262). Beyond the different drugs used, this clinical trial differs from the aforementioned one in some ways: it is not blinded and uses OS as a primary outcome. Results are expected in 2028 after the recruitment of 480 patients.

Until the publication of the results from those phase III trials, some insight will be gained by the many ongoing phase I and II clinical trials also investigating SBRT and immunotherapy for ES NSCLC. The largest of them, the ASTEROID trial (NCT03446547), is a randomized multicenter phase II trial, due to enroll 216 patients with T1-2N0M0 NSCLC receiving adjuvant Durvalumab after SBRT versus SBRT-only (3 or 4 fractions) (116). A 
second randomized phase II trial, led by a team from MD Anderson, will look into SBRT with or without concurrent and adjuvant Nivolumab (117). The recruitment goal is set at 140 patients with stage IIA or less.

\section{SBRT combined with targeted therapies}

Similar to immunotherapy, the established role of targeted therapies in advanced NSCLC has laid the groundwork for their evaluation in ES NSCLC. In 2014, Wang and his colleagues published the results of a prospective study on 14 patients with advanced NSCLC (stages IIIB or IV) (118). Those patients received $250 \mathrm{mg}$ of Gefitinib (epidermal growth factor receptor inhibitor) daily, then concomitant SBRT in three fractions, and continued with Gefitinib for a year or until disease progression. Those patients showed good tolerance of the combined therapy, with few grade 3 toxicities and no grade 4 or higher adverse events. The median follow-up was 15.5 months and the median OS was 19.0 months. One-year local control was $83.9 \%$. As of today, there are no publications studying the interaction of SBRT and targeted therapies in ES NSCLC, and no ongoing trials have been reported either.

\section{Technology oriented research}

\section{Real-time tumor tracking}

With the current technologies available, it is unambiguous to compensate for inter- and intrafractional motion of tumor and internal organs at risk. The most commonly practiced 4D motion compensation strategy uses the so-called internal target volume concept (ITV) with continuously irradiating the target during free breathing (44). The most sophisticated concept for reducing (geometrical) safety margins is the so-called real-time target tracking (119). The process of real-time tumor tracking can be divided into three components: continuous or repetitive assessment of target motion, prediction models to compensate for time delays and non-continuous target monitoring, as well as real-time dynamic motion compensation.

Regular assessment of target motion refers to accommodating respiratory motion by dynamically repositioning the radiation beam in order to follow the tumor location. Tracking of the tumor location can be achieved by radiographically tracking the tumor lesion itself or by tracking of a surrogate structure, using the following four methods (120):

- Radiographic imaging of the lesion itself: Welldefined, natively high-contrasted and conveniently located tumor lesions can potentially be detected in (kv-)imaging acquired during treatment.

- Radiographic imaging of implanted fiducial markers: the implantation of metal fiducial markers allows for detection in $\mathrm{kV}$ imaging or fluoroscopy during treatment, and while a single marker enhances tumor detection, the implantation of multiple markers (three or more) and the measurement of distance between them accounts for tumor motion as well as marker migration.

- Radiographic imaging of a surrogate structure: when continuous imaging of the tumor itself is not feasible, the correlation of the tumor position and an external respiration signal source such as anatomical structures or surface markers can be of use. If the relationship between the tumor position and the surrogate signal is stationary, measurement of the spatial relationship beforehand could be sufficient. However as respiratory physiology is complex, a constant correlation of displacement is not exclusively safe to assume.

- Non-radiographic tracking of implanted signaling devices: Non-radiographic tumor tracking can be achieved by implanting signaling devices, that can be tracked remotely in three dimensions

Treatment delivery system latencies can have a disadvantageous impact during the treatment delivery using real-time tumor tracking systems. Prediction models might help to reduce the tumor localization error and improve gated treatment accuracy (121), while adaptive filter algorithms can be used to adjust for nonstationary correlation of the empirical tumor motion (120).

Real-time dynamic motion compensation can be achieved using MLC compensation, which adapts the leaves opening as the tumor moves. This adaptation is possible using real-time information using the Electronic Portal Imaging Device (122).

Feasibility of MLC tracking has been shown on Varian, Elekta, and Siemens standard linear accelerators (linacs); however, it is not yet commercially available (123-128). The first report of a lung cancer patient treated with implanted electromagnetic transponders and real-time adaptive radiotherapy using MLC tracking was published in 2014 in a non-commercial framework and on a standard linac (127).

Additionally, markerless lung target tracking was performed on a modified programmable platform (HexaMotion, ScandiDos) with a Computerized Imaging Reference Systems (CIRS) phantom mimicking different 


\begin{tabular}{|c|c|c|c|}
\hline \multicolumn{4}{|c|}{ Tracking Methodologies } \\
\hline \multicolumn{2}{|c|}{ Detection of Tumor Motion } & \multicolumn{2}{|c|}{ Compensation of Tumor Motion } \\
\hline $\begin{array}{l}\text { Internal Marker: } \\
\text { - gold marker } \\
\text { - electromagnatic } \\
\text { transponder }\end{array}$ & $\begin{array}{l}\text { Anatomy Tracking } \\
\text { with imaging } \\
\text { modalities: } \\
\text { - fluoroscopy } \\
\text { - ultrasound } \\
\text { - MRI }\end{array}$ & $\begin{array}{l}\text { Tracking: } \\
\text { - MLC } \\
\text { - Couch } \\
\text { - Gimbaled MLC } \\
\text { - Robotic Linac }\end{array}$ & $\begin{array}{l}\text { Gating: } \\
\text { - Normal breathing } \\
\text { - Voluntary breath } \\
\text { hold } \\
\text { - Active breathing } \\
\text { coordinator }\end{array}$ \\
\hline
\end{tabular}

Figure 3 Overview of different tracking methodologies for the detection and compensation of tumor motion. The detection of tumor motion with ultrasound and the compensation of tumor motion with MLC and couch tracking was experimentally proven and is not yet clinically available.

breathing patterns on a standard linac (129) passing all required QA criteria $(119,130,131)$.

Non-ionizing imaging modalities become more and more important to be implemented in combination with real-time motion compensation on standard linear accelerators. Simulating characteristic tumor trajectories in a water tank using a $4 \mathrm{D}$ online ultrasound MLC tracking technique showed promising results to complement the current, commercially available MLC tracking techniques with a noninvasive approach (132). Nevertheless, the main limitation of online ultrasound imaging in general is the speed-of-sound errors in soft tissue with different physical properties leading to a maximum distance error of several millimeters (133). Additionally, MRI-linacs have become commercially available and integrated MR imaging allows for continuous tumor tracking during treatment delivery (134) (Figure 3).

\section{Particle therapy}

The use of SBRT has grown by a factor of three over the past decade and growing numbers of patients with ES NSCLC are expected to be treated in the future (135). However, traditional photon SBRT has some limitations. As outlined above, severe toxicity has been reported in patients with central tumor location. Using an SBRT technique that minimizes the dose to the OARs is desirable in order to reduce radiation-induced toxicity in the primary setting or in the setting of re-irradiation $(136,137)$. In this context, particle therapy $(\mathrm{PT})$ with protons or carbon ions could potentially be advantageous. The unique depth-dose curve characteristics of charged particles compared to photons can be exploited to improve normal tissue sparing without compromising tumor control. In addition to the physical dosimetric advantage, carbon ions also have a biological advantage over photons due to the higher probability of inducing tumor DNA-damage associated with a high linear energy transfer.

Several dosimetric studies comparing PT and photon based SBRT in ES NSCLC have shown that PT can offer comparable or even better coverage than SBRT while reducing the dose to the lungs, heart, esophagus, and spinal cord (138-143). However, it should be noted that the vast majority of the studies comparing dosimetry in ES disease have been performed using the passive scattering technique for PT. These benefits are likely to increase further with the use of pencil beam scanning (PBS) owing to the higher dose conformity, as demonstrated in dosimetric reports (144-147).

Single-arm phase I/II trials and retrospective data for ES disease have shown that proton therapy results in lung toxicities no greater than grade 3, the ability of dose escalation, and 2-year OS rates of 74-97.8\% (148-151). For carbon ion radiotherapy, Japanese studies have reported OS rates at 3 and 5 years of $75 \%$ and $45-50 \%$, respectively (152-154). Although these studies are promising, they were performed using the passive scattering technique and conventionally fractionated or hypofractionated schemes that are no longer used in the ES setting. A recent retrospective study has investigated the safety and efficacy of PT using pencil beam scanning for ES NSCLC (155). It has been observed that PBS-based PT is associated with PFS, LC, and OS rates at 2-year of $85.5 \%, 95.2 \%$, and $90.7 \%$, respectively, with mild acute and late toxicities.

Despite these encouraging results, the optimal clinical context for PT is still unclear. There are currently no clinical data demonstrating a clear benefit of hypofractionated PT over SBRT for ES NSCLC. A meta- 
analysis comparing the two modalities suggested that there is no statistically significant survival benefit from PT over SBRT after the inclusion of operability, but the 3-years LC favored PT (156). It should be emphasized that the study reported no indication of the inferiority of $\mathrm{PT}$ compared to SBRT, although almost all PBT patients were treated with passive scattering technique and without image guidance.

To date, there is only one report on phase II randomized study comparing SBRT and stereotactic body proton therapy in ES NSCLC by MD Anderson (157). The trial closed early due to low accrual attributable to the lack of volumetric image-guided radiotherapy (IGRT) and insurance coverage. Nonetheless, the authors concluded that both techniques have acceptable toxicity and lead to comparable results.

In light of these results, further comparisons between $\mathrm{PT}$ and SBRT in randomized studies that use advanced techniques are warranted to define the role of $\mathrm{PT}$ in ES NSCLC.

\section{FLASH radiotherapy}

In the past decades, advances in high-precision radiotherapy treatment delivery and image guidance have led to significant improvements in the management of lung cancers. However, tumor motion during treatment remains clinically challenging to address. Recently, FLASH radiotherapy has emerged as a technique able to "freeze" intra-fraction motion as it involves the ultra-fast delivery of treatment at dose rates exceeding by several orders of magnitude those currently used in clinical practice. Moreover, many pre-clinical studies across different animal models have shown that FLASH radiotherapy has the potential to markedly improve normal tissue tolerance while maintaining tumor control level (the so-called FLASH effect) (158-160). In a pioneering study on the FLASH effect, Favaudon et al. investigated lung fibrogenesis in C57BL/6J mice after bilateral thorax exposure to pulsed, ultra-high dose rates $(\geq 40 \mathrm{~Gy} / \mathrm{s})$ irradiation with $4.5 \mathrm{MeV}$ electron beams given in a single dose (161). Results showed that FLASH irradiation protects lungs from radiationinduced fibrosis at doses known to trigger the development of fibrosis in the totality of animals after conventional doserate irradiation $(\leq 0.03 \mathrm{~Gy} / \mathrm{s})$. Cutaneous lesions were also reduced in severity, without modifying the anti-tumor efficiency compared to conventional irradiation.

To date, most studies investigating the FLASH effect have been performed using dedicated electron linear accelerators as a source of radiation, thus limiting its clinical viability in practice. It was recently shown that clinacs can be modified for delivery of FLASH radiotherapy with electrons, thus increasing the potential availability of FLASH irradiators and facilitating its clinical translation $(162,163)$. However, the poor penetration depth of 4.5 $20 \mathrm{MeV}$ electron beams limits FLASH radiotherapy to the treatment of superficial tumors only, or in the intraoperative radiation therapy (IORT) setting. Whilst US researchers are developing the PHASER platform that might represent the ideal approach to bring FLASH with high-energy X-ray beams into clinic (164), to date, FLASH radiotherapy treatment of deep-seated tumors could potentially be performed only with proton beams. In fact, it has already been shown that modern proton therapy systems are potentially able to produce beams at very high intensities (165), and it is now being investigated if FLASH dose rates can be achieved for clinical proton therapy treatments (166).

\section{Radiomics}

Cross-sectional imaging is a pillar of modern diagnosis. With the steady improvement of imaging quality and the increase of imaging availability over the last decades, more and more valuable data is available for extraction and interpretation. Radiomics is a fast emerging research field, yielding to harness imaging features and provide additional quantitative information to build prediction models and/ or characterize cancer phenotypes. Radiomics is currently evaluated for two purposes: pre-treatment risk assessment of ES NSCLC and post-SBRT assessment of radiationinduced fibrosis versus local tumor recurrence.

A study analyzing a longitudinal 18F-FDG-PET/CT dataset of 100 consecutive patients (ES NSCLC) reported that an unsupervised machine learning method based on 722 radiomics features showed promising outcome prediction compared to prediction models based on clinical characteristics only (167). Such models would be highly desirable for selection of high-risk patients, which might benefit the most from treatment intensification.

Post-SBRT fibrotic changes are frequently difficult to distinguish from true recurrence after SBRT for ES NSCLC: longitudinal CT imaging improves the accuracy but might put the patient at an increased risk for further disease progression. Early studies have shown promising results of using radiomics for post-SBRT follow-up imaging. Mattonen et al. reported a study of 45 patients, 15 with local recurrence matched to 30 without, where radiomics was able to accurately predict local recurrence as 
early as 6 months after SBRT (168).

Despite the promise of Radiomics, its prospective evaluation especially in a multi-institutional environment, with varying imaging hardware and protocols needs to be demonstrated.

\section{Conclusions}

The advances in SBRT technology over the last decades and the increasing availability of SBRT expertise and infrastructures have established SBRT as a safe, effective and efficient treatment option for ES NSCLC, which is today the standard of care for inoperable patients. While treatment of peripheral lesions indisputably results in excellent outcome and rare major side effects, centrally located lesions are more prone to develop treatmentrelated toxicity. The latter can be treated safely using adapted dose/fractionation regimes; however, research on the optimal relationship between fractionation schedules and tumor location is ongoing. In medically operable patients, surgical resection remains the preferred treatment, although SBRT has been shown to yield comparable results. SBRT is therefore a valid alternative for appropriately selected patients, however further randomized evidence is called for. Onward perspectives in SBRT may include the implementation of technological advances as well as treatment combinations (e.g., targeted substances) in order to further improve outcome and reduce toxicity.

\section{Acknowledgments}

Funding: None.

\section{Footnote}

Provenance and Peer Review: This article was commissioned by the Guest Editors (Jacek Jassem and Rafal Dziadziuszko) for the series "Radiotherapy in thoracic malignancies" published in Translational Lung Cancer Research. The article has undergone external peer review.

Peer Review File: Available at http://dx.doi.org/10.21037/ tlcr-20-860

Conflicts of Interest: All authors have completed the ICMJE uniform disclosure form (available at http://dx.doi. org/10.21037/tlcr-20-860). The series "Radiotherapy in thoracic malignancies" was commissioned by the editorial office without any funding or sponsorship. MG reports grants from Varian, AstraZeneca and Viewray, unrelated to this work. The authors have no other conflicts of interest to declare.

Ethical Statement: The authors are accountable for all aspects of the work in ensuring that questions related to the accuracy or integrity of any part of the work are appropriately investigated and resolved. All figures and tables are original figures and tables.

Open Access Statement: This is an Open Access article distributed in accordance with the Creative Commons Attribution-NonCommercial-NoDerivs 4.0 International License (CC BY-NC-ND 4.0), which permits the noncommercial replication and distribution of the article with the strict proviso that no changes or edits are made and the original work is properly cited (including links to both the formal publication through the relevant DOI and the license). See: https://creativecommons.org/licenses/by-nc-nd/4.0/.

\section{References}

1. Bray F, Ferlay J, Soerjomataram I, et al. Global cancer statistics 2018: GLOBOCAN estimates of incidence and mortality worldwide for 36 cancers in 185 countries. CA Cancer J Clin 2018;68:394-424.

2. SEER Cancer Statistics Review, 1975-2016 [Internet]. SEER. [zitiert 5. April 2020]. Available online: https://seer. cancer.gov/csr/1975_2016/index.html

3. de Koning HJ, van der Aalst CM, de Jong PA, et al. Reduced Lung-Cancer Mortality with Volume CT Screening in a Randomized Trial. N Engl J Med 2020;382:503-13.

4. Team TNLSTR. Reduced Lung-Cancer Mortality with Low-Dose Computed Tomographic Screening [Internet]. http://dx.doi.org/10.1056/NEJMoa1102873. Massachusetts Medical Society; 2011 [zitiert 3. Juli 2020]. Available online: https://www.nejm.org/doi/10.1056/ NEJMoa1 102873

5. Rami-Porta R, Bolejack V, Crowley J, et al. The IASLC Lung Cancer Staging Project: Proposals for the Revisions of the T Descriptors in the Forthcoming Eighth Edition of the TNM Classification for Lung Cancer. J Thorac Oncol 2015;10:990-1003.

6. Dalwadi SM, Szeja SS, Bernicker EH, et al. Practice Patterns and Outcomes in Elderly Stage I Non-Small-cell Lung Cancer: A 2004 to 2012 SEER Analysis. Clin Lung 
Cancer 2018;19:e269-76.

7. Ricardi U, Filippi AR, Guarneri A, et al. Stereotactic body radiation therapy for early stage non-small cell lung cancer: Results of a prospective trial. Lung Cancer 2010;68:72-7.

8. Potters L, Kavanagh B, Galvin JM, et al. American Society for Therapeutic Radiology and Oncology (ASTRO) and American College of Radiology (ACR) practice guideline for the performance of stereotactic body radiation therapy. Int J Radiat Oncol Biol Phys 2010;76:326-32.

9. Lax I, Blomgren H, Näslund I, Svanström R. Stereotactic Radiotherapy of Malignancies in the Abdomen: Methodological aspects. Acta Oncol 1994;33:677-83.

10. Uematsu M, Shioda A, Tahara K, et al. Focal, high dose, and fractionated modified stereotactic radiation therapy for lung carcinoma patients: a preliminary experience. Cancer 1998;82:1062-70.

11. Koto M, Takai Y, Ogawa Y, et al. A phase II study on stereotactic body radiotherapy for stage I non-small cell lung cancer. Radiother Oncol 2007;85:429-34.

12. Lindberg K, Bergström P, Brustugun OT, et al. OA24.05 The Nordic HILUS-Trial - First Report of a Phase II Trial of SBRT of Centrally Located Lung Tumors. J Thorac Oncol 2017;12:S340.

13. Onishi H, Shirato H, Nagata Y, et al. Hypofractionated Stereotactic Radiotherapy (HypoFXSRT) for Stage I Nonsmall Cell Lung Cancer: Updated Results of 257 Patients in a Japanese Multi-institutional Study. J Thorac Oncol 2007;2:S94-100.

14. Baumann P, Nyman J, Hoyer M, et al. Outcome in a prospective phase II trial of medically inoperable stage I non-small-cell lung cancer patients treated with stereotactic body radiotherapy. J Clin Oncol 2009;27:3290-6.

15. Lagerwaard FJ, Haasbeek CJA, Smit EF, Slotman BJ, Senan S. Outcomes of Risk-Adapted Fractionated Stereotactic Radiotherapy for Stage I Non-Small-Cell Lung Cancer. Int J Radiat Oncol Biol Phys 2008;70:685-92.

16. Xia T, Li H, Sun Q, et al. Promising clinical outcome of stereotactic body radiation therapy for patients with inoperable Stage I/II non-small-cell lung cancer. Int J Radiat Oncol Biol Phys 2006;66:117-25.

17. Nyman J, Hallqvist A, Lund JA, et al. SPACE - A randomized study of SBRT vs conventional fractionated radiotherapy in medically inoperable stage I NSCLC. Radiother Oncol 2016;121:1-8.

18. Timmerman R, Paulus R, Galvin J, et al. Stereotactic Body Radiation Therapy for Inoperable Early Stage Lung
Cancer. JAMA 2010;303:1070-6.

19. Zimmermann FB, Geinitz H, Schill S, et al. Stereotactic hypofractionated radiotherapy in stage I (T1-2 N0 M0) non-small-cell lung cancer (NSCLC). Acta Oncol 2006;45:796-801.

20. Ball D, Mai GT, Vinod S, et al. Stereotactic ablative radiotherapy versus standard radiotherapy in stage 1 nonsmall-cell lung cancer (TROG 09.02 CHISEL): a phase 3 , open-label, randomised controlled trial. Lancet Oncol 2019;20:494-503.

21. Lindberg K, Nyman J, Källskog VR, et al. Longterm results of a prospective phase II trial of medically inoperable stage I NSCLC treated with SBRT - the Nordic experience. Acta Oncol 2015;54:1096-104.

22. Guckenberger M, Andratschke N, Dieckmann K, et al. ESTRO ACROP consensus guideline on implementation and practice of stereotactic body radiotherapy for peripherally located early stage non-small cell lung cancer. Radiother Oncol 2017;124:11-7.

23. Postmus PE, Kerr KM, Oudkerk M, et al. Early and locally advanced non-small-cell lung cancer (NSCLC): ESMO Clinical Practice Guidelines for diagnosis, treatment and follow-up†. Ann Oncol 2017;28:iv1-21.

24. Videtic GMM, Donington J, Giuliani M, et al. Stereotactic body radiation therapy for early-stage non-small cell lung cancer: Executive Summary of an ASTRO Evidence-Based Guideline. Pract Radiat Oncol 2017;7:295-301.

25. Wood DE. National Comprehensive Cancer Network (NCCN) Clinical Practice Guidelines for Lung Cancer Screening. Thorac Surg Clin 2015;25:185-97.

26. Guckenberger M, Allgäuer M, Appold S, et al. Safety and Efficacy of Stereotactic Body Radiotherapy for Stage I Non-Small-Cell Lung Cancer in Routine Clinical Practice: A Patterns-of-Care and Outcome Analysis. J Thorac Oncol 2013;8:1050-8.

27. Vansteenkiste J, Crinò L, Dooms C, et al. 2nd ESMO Consensus Conference on Lung Cancer: early-stage nonsmall-cell lung cancer consensus on diagnosis, treatment and follow-up. Ann Oncol 2014;25:1462-74.

28. Senthi S, Lagerwaard FJ, Haasbeek CJ, et al. Patterns of disease recurrence after stereotactic ablative radiotherapy for early stage non-small-cell lung cancer: a retrospective analysis. Lancet Oncol 2012;13:802-9.

29. Timmerman RD, Hu C, Michalski J, et al. Long-term Results of RTOG 0236: A Phase II Trial of Stereotactic Body Radiation Therapy (SBRT) in the Treatment of Patients with Medically Inoperable Stage I Non-Small Cell Lung Cancer. Int J Radiat Oncol Biol Phys 2014;90:S30. 
30. Peulen H, Mantel F, Guckenberger M, et al. Validation of High-Risk Computed Tomography Features for Detection of Local Recurrence After Stereotactic Body Radiation Therapy for Early-Stage Non-Small Cell Lung Cancer. Int J Radiat Oncol Biol Phys 2016;96:134-41.

31. Huang K, Senthi S, Palma DA, et al. High-risk CT features for detection of local recurrence after stereotactic ablative radiotherapy for lung cancer. Radiother Oncol 2013;109:51-7.

32. Chang JY, Senan S, Paul MA, et al. Stereotactic ablative radiotherapy versus lobectomy for operable stage I nonsmall-cell lung cancer: a pooled analysis of two randomised trials. Lancet Oncol 2015;16:630-7.

33. Lagerwaard FJ, Verstegen NE, Haasbeek CJA, et al. Outcomes of Stereotactic Ablative Radiotherapy in Patients With Potentially Operable Stage I NonSmall Cell Lung Cancer. Int J Radiat Oncol Biol Phys 2012;83:348-53

34. Timmerman RD, Paulus R, Pass HI, et al. Stereotactic Body Radiation Therapy for Operable Early-Stage Lung Cancer: Findings From the NRG Oncology RTOG 0618 Trial. JAMA Oncol 2018;4:1263-6.

35. Nagata Y, Hiraoka M, Shibata T, et al. Prospective Trial of Stereotactic Body Radiation Therapy for Both Operable and Inoperable T1N0M0 Non-Small Cell Lung Cancer: Japan Clinical Oncology Group Study JCOG0403. Int J Radiat Oncol Biol Phys 2015;93:989-96.

36. Onishi H, Shioyama Y, Matsumoto Y, et al. Japanese Multi-institutional Study of Stereotactic Body Radiation Therapy for 661 Medically Operable Patients With Stage I Non-Small Cell Lung Cancer. Int J Radiat Oncol Biol Phys 2015;93:S187.

37. Zheng X, Schipper M, Kidwell K, et al. Survival outcome after stereotactic body radiation therapy and surgery for stage I non-small cell lung cancer: a meta-analysis. Int J Radiat Oncol Biol Phys 2014;90:603-11.

38. Cao C, Wang D, Chung C, et al. A systematic review and meta-analysis of stereotactic body radiation therapy versus surgery for patients with non-small cell lung cancer. J Thorac Cardiovasc Surg 2019;157:362-373.e8.

39. Chen H, Laba JM, Boldt RG, et al. Stereotactic Ablative Radiation Therapy Versus Surgery in Early Lung Cancer: A Meta-analysis of Propensity Score Studies. Int J Radiat Oncol Biol Phys 2018;101:186-94.

40. Benedict SH, Yenice KM, Followill D, et al. Stereotactic body radiation therapy: The report of AAPM Task Group 101. Med Phys 2010;37:4078-101.

41. Halvorsen PH, Cirino E, Das IJ, et al. AAPM-RSS
Medical Physics Practice Guideline 9.a. for SRS-SBRT. J Appl Clin Med Phys 2017;18:10-21.

42. Schmitt D, Blanck O, Gauer T, et al. Technological quality requirements for stereotactic radiotherapy. Strahlenther Onkol [Internet]. 24. März 2020 [zitiert 16. April 2020]; Available online: https://doi.org/10.1007/s00066-02001583-2

43. Task Group 142 report: Quality assurance of medical acceleratorsa) - Klein - 2009 - Medical Physics - Wiley Online Library [Internet]. [zitiert 16. April 2020].

Available online: https://aapm.onlinelibrary.wiley.com/doi/ full/10.1118/1.3190392

44. Guckenberger M, Andratschke N, Alheit H, et al. Definition of stereotactic body radiotherapy. Strahlenther Onkol 2014;190:26-33.

45. Timmerman R, McGarry R, Yiannoutsos C, et al. Excessive toxicity when treating central tumors in a phase II study of stereotactic body radiation therapy for medically inoperable early-stage lung cancer. J Clin Oncol 2006;24:4833-9.

46. Bezjak A, Paulus R, Gaspar LE, et al. Efficacy and Toxicity Analysis of NRG Oncology/RTOG 0813 Trial of Stereotactic Body Radiation Therapy (SBRT) for Centrally Located Non-Small Cell Lung Cancer (NSCLC). Int J Radiat Oncol Biol Phys 2016;96:S8.

47. Saito M, Furukawa K, Miura T, et al. Evaluation of $\mathrm{T}$ factor, surgical method, and prognostic factors in central type lung cancer. Jpn J Thorac Cardiovasc Surg 2002;50:413-7.

48. Senthi S, Haasbeek CJA, Slotman BJ, et al. Outcomes of stereotactic ablative radiotherapy for central lung tumours: a systematic review. Radiother Oncol 2013;106:276-82.

49. Chaudhuri AA, Tang C, Binkley MS, et al. Stereotactic ablative radiotherapy (SABR) for treatment of central and ultra-central lung tumors. Lung Cancer 2015;89:50-6.

50. Tekatli H, Haasbeek N, Dahele M, et al. Outcomes of Hypofractionated High-Dose Radiotherapy in Poor-Risk Patients with "Ultracentral” Non-Small Cell Lung Cancer. J Thorac Oncol 2016;11:1081-9.

51. Modh A, Rimner A, Williams E, et al. Local control and toxicity in a large cohort of central lung tumors treated with stereotactic body radiation therapy. Int J Radiat Oncol Biol Phys 2014;90:1168-76.

52. Park HS, Harder EM, Mancini BR, et al. Central versus Peripheral Tumor Location: Influence on Survival, Local Control, and Toxicity Following Stereotactic Body Radiotherapy for Primary Non-Small-Cell Lung Cancer. J Thorac Oncol 2015;10:832-7. 
53. Mangona VS, Aneese AM, Marina O, et al. Toxicity after central versus peripheral lung stereotactic body radiation therapy: a propensity score matched-pair analysis. Int J Radiat Oncol Biol Phys 2015;91:124-32.

54. Adebahr S, Collette S, Shash E, et al. LungTech, an EORTC Phase II trial of stereotactic body radiotherapy for centrally located lung tumours: a clinical perspective. Br J Radiol 2015;88:20150036.

55. LungTech: Stereotactic Body Radiotherapy (SBRT) of Inoperable Centrally Located NSCLC - Tabular View - ClinicalTrials.gov [Internet]. [zitiert 1. Juli 2020]. Available online: https:/clinicaltrials.gov/ct2/show/record/ NCT01795521

56. Wang C, Sidiqi BU, Yorke ED, et al. Toxicity and Local Control in "Ultra-Central" Lung Tumors Treated with Stereotactic Body Radiation Therapy (SBRT). Int J Radiat Oncol Biol Phys 2018;102:S10.

57. Nguyen KNB, Hause DJ, Novak J, et al. Tumor Control and Toxicity after SBRT for Ultracentral, Central, and Paramediastinal Lung Tumors. Pract Radiat Oncol 2019;9:e196-202.

58. Zhao Y, Khawandanh E, Thomas S, et al. Outcomes of stereotactic body radiotherapy $60 \mathrm{~Gy}$ in 8 fractions when prioritizing organs at risk for central and ultracentral lung tumors. Radiat Oncol 2020;15:61.

59. Giuliani M, Mathew AS, Bahig H, et al. SUNSET: Stereotactic Radiation for Ultracentral Non-Small-Cell Lung Cancer-A Safety and Efficacy Trial. Clin Lung Cancer 2018;19:e529-32.

60. Chang JY, Bezjak A, Mornex F. Stereotactic Ablative Radiotherapy for Centrally Located Early Stage NonSmall-Cell Lung Cancer: What We Have Learned. J Thorac Oncol 2015;10:577-85.

61. Haasbeek CJA, Lagerwaard FJ, Slotman BJ, et al. Outcomes of Stereotactic Ablative Radiotherapy for Centrally Located Early-Stage Lung Cancer. J Thorac Oncol 2011;6:2036-43.

62. Li Q, Swanick CW, Allen PK, et al. Stereotactic ablative radiotherapy (SABR) using 70 Gy in 10 fractions for nonsmall cell lung cancer: exploration of clinical indications. Radiother Oncol 2014;112:256-61.

63. Haseltine JM, Rimner A, Gelblum DY, et al. Fatal complications after stereotactic body radiation therapy for central lung tumors abutting the proximal bronchial tree. Pract Radiat Oncol 2016;6:e27-33.

64. Bezjak A, Paulus R, Gaspar LE, et al. Safety and Efficacy of a Five-Fraction Stereotactic Body Radiotherapy Schedule for Centrally Located Non-Small-Cell Lung
Cancer: NRG Oncology/RTOG 0813 Trial. J Clin Oncol 2019;37:1316-25.

65. Stam B, Grills IS, Kwint M, et al. SBRT for Central Tumors in Early Stage NSCLC Patients. Int J Radiat Oncol Biol Phys 2017;99:S17.

66. Daly M, Novak J, Monjazeb A. P2.05-056 Safety of Stereotactic Body Radiotherapy for Central, Ultracentral, and Paramediastinal Lung Tumors: Topic: Toxicities. J Thorac Oncol 2017;12:S1066.

67. Roach MC, Robinson CG, DeWees TA, et al. Stereotactic Body Radiation Therapy for Central Early-Stage NSCLC: Results of a Prospective Phase I/II Trial. J Thorac Oncol 2018;13:1727-32.

68. Early-Stage and Locally Advanced (non-metastatic) NonSmall-Cell Lung Cancer I ESMO [Internet]. [zitiert 27. März 2020]. Available online: https://www.esmo.org/ guidelines/lung-and-chest-tumours/early-stage-andlocally-advanced-non-metastatic-non-small-cell-lungcancer

69. Herder GJ, van Tinteren H, Golding RP, et al. Clinical prediction model to characterize pulmonary nodules: validation and added value of $18 \mathrm{~F}$-fluorodeoxyglucose positron emission tomography. Chest 2005;128:2490-6.

70. Takeda A, Kunieda E, Sanuki N, et al. Stereotactic body radiotherapy (SBRT) for solitary pulmonary nodules clinically diagnosed as lung cancer with no pathological confirmation: comparison with non-small-cell lung cancer. Lung Cancer 2012;77:77-82.

71. Verstegen NE, Lagerwaard FJ, Haasbeek CJA, et al. Outcomes of stereotactic ablative radiotherapy following a clinical diagnosis of stage I NSCLC: comparison with a contemporaneous cohort with pathologically proven disease. Radiother Oncol 2011;101:250-4.

72. Wegner RE, Ahmed N, Hasan S, et al. SBRT for early stage lung cancer: outcomes from biopsy-proven and empirically treated lesions. Lung Cancer Manag [Internet]. 17. April 2018 [zitiert 15. April 2020];7(1). Available online: https://www.ncbi.nlm.nih.gov/pmc/articles/ PMC6307539/

73. Haidar YM, Rahn DA, Nath S, et al. Comparison of outcomes following stereotactic body radiotherapy for non-small cell lung cancer in patients with and without pathological confirmation. Ther Adv Respir Dis 2014;8:3-12.

74. Hasan S, Colonias A, Mickus T, et al. Image based management of empiric lung stereotactic body radiotherapy (SBRT) without biopsy: Predictors from a 10 year single institution experience. Thorac Cancer 
2018;9:699-706.

75. Inoue T, Katoh N, Ito YM, et al. Stereotactic body radiotherapy to treat small lung lesions clinically diagnosed as primary lung cancer by radiological examination: A prospective observational study. Lung Cancer 2018;122:107-12.

76. IJsseldijk MA, Shoni M, Siegert C, et al. Survival After Stereotactic Body Radiation Therapy for Clinically Diagnosed or Biopsy-Proven Early-Stage NSCLC: A Systematic Review and Meta-Analysis. J Thorac Oncol 2019;14:583-95.

77. Bradley B, Branley HM, Egan JJ, et al. Interstitial lung disease guideline: the British Thoracic Society in collaboration with the Thoracic Society of Australia and New Zealand and the Irish Thoracic Society. Thorax 2008;63 Suppl 5:v1-58.

78. Brown AW, Shlobin OA, Weir N, et al. Dynamic Patient Counseling: A Novel Concept in Idiopathic Pulmonary Fibrosis. Chest 2012;142:1005-10.

79. Raghu G, Nyberg F, Morgan G. The epidemiology of interstitial lung disease and its association with lung cancer. Br J Cancer 2004;91:S3-10.

80. Sanuki N, Ono A, Komatsu E, et al. Association of Computed Tomography-detected Pulmonary Interstitial Changes with Severe Radiation Pneumonitis for Patients Treated with Thoracic Radiotherapy. J Radiat Res (Tokyo) 2012;53:110-6.

81. Ozawa Y, Abe T, Omae M, et al. Impact of Preexisting Interstitial Lung Disease on Acute, Extensive Radiation Pneumonitis: Retrospective Analysis of Patients with Lung Cancer. PLoS One 2015;10:e0140437.

82. Lee YH, Kim YS, Lee SN, et al. Interstitial Lung Change in Pre-radiation Therapy Computed Tomography Is a Risk Factor for Severe Radiation Pneumonitis. Cancer Res Treat 2015;47:676-86.

83. Yamaguchi S, Ohguri T, Matsuki Y, et al. Radiotherapy for thoracic tumors: association between subclinical interstitial lung disease and fatal radiation pneumonitis. Int J Clin Oncol 2015;20:45-52.

84. Ueki N, Matsuo Y, Togashi Y, et al. Impact of pretreatment interstitial lung disease on radiation pneumonitis and survival after stereotactic body radiation therapy for lung cancer. J Thorac Oncol 2015;10:116-25.

85. Bahig H, Filion E, Vu T, et al. Severe radiation pneumonitis after lung stereotactic ablative radiation therapy in patients with interstitial lung disease. Pract Radiat Oncol 2016;6:367-74.

86. Glick D, Lyen S, Kandel S, et al. Impact of Pretreatment
Interstitial Lung Disease on Radiation Pneumonitis and Survival in Patients Treated With Lung Stereotactic Body Radiation Therapy (SBRT). Clin Lung Cancer 2018;19:e219-26.

87. Yamaguchi S, Ohguri T, Ide S, et al. Stereotactic body radiotherapy for lung tumors in patients with subclinical interstitial lung disease: the potential risk of extensive radiation pneumonitis. Lung Cancer 2013;82:260-5.

88. Yamashita H, Kobayashi-Shibata S, Terahara A, et al. Prescreening based on the presence of CT-scan abnormalities and biomarkers (KL-6 and SP-D) may reduce severe radiation pneumonitis after stereotactic radiotherapy. Radiat Oncol 2010;5:32.

89. Verstegen NE, Maat APWM, Lagerwaard FJ, et al. Salvage surgery for local failures after stereotactic ablative radiotherapy for early stage non-small cell lung cancer. Radiat Oncol 2016;11:131.

90. Antonoff MB, Correa AM, Sepesi B, et al. Salvage pulmonary resection after stereotactic body radiotherapy: A feasible and safe option for local failure in selected patients. J Thorac Cardiovasc Surg 2017;154:689-99.

91. Hamaji M, Chen-Yoshikawa TF, Matsuo Y, et al. Salvage video-assisted thoracoscopic lobectomy for isolated local relapse after stereotactic body radiotherapy for early stage non-small cell lung cancer: technical aspects and perioperative management. J Vis Surg 2017;3:86.

92. Ogawa Y, Shibamoto Y, Hashizume C, et al. Repeat stereotactic body radiotherapy (SBRT) for local recurrence of non-small cell lung cancer and lung metastasis after first SBRT. Radiat Oncol 2018;13:136.

93. Hearn JWD, Videtic GMM, Djemil T, et al. Salvage stereotactic body radiation therapy (SBRT) for local failure after primary lung SBRT. Int J Radiat Oncol Biol Phys 2014;90:402-6.

94. Trakul N, Harris JP, Le QT, et al. Stereotactic ablative radiotherapy for reirradiation of locally recurrent lung tumors. J Thorac Oncol 2012;7:1462-5.

95. Peulen H, Karlsson K, Lindberg K, et al. Toxicity after reirradiation of pulmonary tumours with stereotactic body radiotherapy. Radiother Oncol 2011;101:260-6.

96. Patel NR, Lanciano R, Sura K, et al. Stereotactic body radiotherapy for re-irradiation of lung cancer recurrence with lower biological effective doses. J Radiat Oncol 2015;4:65-70.

97. Kilburn JM, Kuremsky JG, Blackstock AW, et al. Thoracic re-irradiation using stereotactic body radiotherapy (SBRT) techniques as first or second course of treatment. Radiother Oncol 2014;110:505-10. 
98. Meijneke TR, Petit SF, Wentzler D, et al. Reirradiation and stereotactic radiotherapy for tumors in the lung: dose summation and toxicity. Radiother Oncol 2013;107:423-7.

99. Kennedy WR, Gabani P, Nikitas J, et al. Repeat stereotactic body radiation therapy (SBRT) for salvage of isolated local recurrence after definitive lung SBRT. Radiother Oncol 2020;142:230-5.

100. Nonaka H, Onishi H, Ozaki M, et al. Serious gastric perforation after second stereotactic body radiotherapy for peripheral lung cancer that recurred after initial stereotactic body radiotherapy: a case report. J Med Case Rep 2017;11:343.

101. Nguyen NA, Isfahanian N, Pond G, et al. A Novel Neoadjuvant Therapy for Operable Locally Invasive NonSmall-Cell Lung Cancer. Phase I Study of Neoadjuvant Stereotactic Body Radiotherapy. LINNEARRE I (NCT02433574). Clin Lung Cancer 2017;18:436-440.e1.

102.Palma DA, Nguyen TK, Kwan K, et al. Short report: interim safety results for a phase II trial measuring the integration of stereotactic ablative radiotherapy (SABR) plus surgery for early stage non-small cell lung cancer (MISSILE-NSCLC). Radiat Oncol 2017;12:30.

103. Fernando HC, Timmerman R. American College of Surgeons Oncology Group Z4099/Radiation Therapy Oncology Group 1021: a randomized study of sublobar resection compared with stereotactic body radiotherapy for high-risk stage I non-small cell lung cancer. J Thorac Cardiovasc Surg 2012;144:S35-8.

104. Franks K, Mcparland L, Webster J, et al. P2.16-16 SABRTOOTH: A Fasibility Study of SABR Versus Surgery in Patients with Peripheral Stage I NSCLC Considered to be at Higher Risk for Surgery. J Thorac Oncol 2018;13:S837.

105. Radical Resection Vs. Ablative Stereotactic Radiotherapy in Patients With Operable Stage I NSCLC - Tabular View - ClinicalTrials.gov [Internet]. [zitiert 6. April 2020]. Available online: https://clinicaltrials.gov/ct2/show/record/ NCT01753414

106. Veterans Affairs Lung Cancer Surgery Or Stereotactic Radiotherapy - Full Text View - ClinicalTrials.gov [Internet]. [zitiert 6. April 2020]. Available online: https:// clinicaltrials.gov/ct2/show/NCT02984761

107.JoLT-Ca Sublobar Resection (SR) Versus Stereotactic Ablative Radiotherapy (SAbR) for Lung Cancer - Full Text View - ClinicalTrials.gov [Internet]. [zitiert 6. April 2020]. Available online: https://clinicaltrials.gov/ct2/show/ NCT02468024

108. Robinson CG, DeWees TA, El Naqa IM, et al. Patterns of Failure after Stereotactic Body Radiation Therapy or Lobar Resection for Clinical Stage I Non-Small-Cell Lung Cancer. J Thorac Oncol 2013;8:192-201.

109. Foster CC, Rusthoven CG, Sher DJ, et al. Adjuvant chemotherapy following stereotactic body radiotherapy for early stage non-small-cell lung cancer is associated with lower overall: A National Cancer Database Analysis. Lung Cancer 2019;130:162-8.

110. Chen Y, Guo W, Lu Y, et al. Dose-individualized stereotactic body radiotherapy for T1-3N0 non-small cell lung cancer: long-term results and efficacy of adjuvant chemotherapy. Radiother Oncol 2008;88:351-8.

111. Verma V, McMillan MT, Grover S, et al. Stereotactic Body Radiation Therapy and the Influence of Chemotherapy on Overall Survival for Large ( $\geq 5$ Centimeter) NonSmall Cell Lung Cancer. Int J Radiat Oncol Biol Phys 2017;97:146-54.

112. Borghaei H, Paz-Ares L, Horn L, et al. Nivolumab versus Docetaxel in Advanced Nonsquamous Non-Small-Cell Lung Cancer. N Engl J Med 2015;373:1627-39.

113.Daly M, Monjazeb A, Mirhadi A, et al. MA02.07 A Phase I Trial of an Immune Checkpoint Inhibitor Plus Stereotactic Ablative Radiotherapy in Patients with Early Stage NonSmall Cell Lung Cancer. J Thorac Oncol 2019;14:S254.

114. AstraZeneca. A Phase III, Randomized, Placebocontrolled, Double-blind, Multi-center, International Study of Durvalumab Following Stereotactic Body Radiation Therapy (SBRT) for the Treatment of Patients With Unresected Stage I/II, Lymph-node Negative Nonsmall Cell Lung Cancer (PACIFIC-4/RTOG-3515) [Internet]. clinicaltrials.gov; 2020 Mai [zitiert 22. Mai 2020]. Report No.: NCT03833154. Available online: https://clinicaltrials.gov/ct2/show/NCT03833154

115. National Cancer Institute (NCI). A Randomized Phase III Trial of Induction/Consolidation Atezolizumab (NSC \#783608) + SBRT Versus SBRT Alone in High Risk, Early Stage NSCLC [Internet]. clinicaltrials.gov; 2020 Mai [zitiert 22. Mai 2020]. Report No.: NCT04214262. Available online: https://clinicaltrials.gov/ct2/show/ NCT04214262

116. Hallqvist A. Identifier NCT03446547 - Ablative STEreotactic RadiOtherapy wIth Durvalumab (MEDI4736) (ASTEROID) [Internet]. ClinicalTrials.gov. 2018 [zitiert 29. März 2020]. Available online: https:// clinicaltrials.gov/ct2/show/NCT03446547

117. Chang JY. Identifier NCT03110978 - Stereotactic Body Radiation Therapy With or Without Nivolumab in Treating Patients With Stage I-IIA or Recurrent Non- 
small Cell Lung Cancer [Internet]. ClinicalTrials.gov. 2017 [zitiert 29. März 2020]. Available online: https:// clinicaltrials.gov/ct2/show/NCT03110978

118. Wang Z, Zhu XX, Wu XH, et al. Gefitinib Combined With Stereotactic Radiosurgery in Previously Treated Patients With Advanced Non-Small Cell Lung Cancer: Am J Clin Oncol 2014;37:148-53.

119.Santanam L, Noel C, Willoughby TR, et al. Quality assurance for clinical implementation of an electromagnetic tracking system: Quality assurance of an electromagnetic tracking system. Med Phys 2009;36:3477-86.

120. Keall PJ, Mageras GS, Balter JM, et al. The management of respiratory motion in radiation oncology report of AAPM Task Group 76a). Med Phys 2006;33:3874-900.

121. Sharp GC, Jiang SB, Shimizu S, et al. Prediction of respiratory tumour motion for real-time image-guided radiotherapy. Phys Med Biol 2004;49:425-440.

122. Rottmann J, Keall P, Berbeco R. Real-time soft tissue motion estimation for lung tumors during radiotherapy delivery. Med Phys 2013;40:091713.

123. Krauss A, Nill S, Tacke M, et al. Electromagnetic RealTime Tumor Position Monitoring and Dynamic Multileaf Collimator Tracking Using a Siemens 160 MLC: Geometric and Dosimetric Accuracy of an Integrated System. Int J Radiat Oncol Biol Phys 2011;79:579-87.

124. Davies GA, Poludniowski G, Webb S. MLC tracking for Elekta VMAT: a modelling study. Phys Med Biol 2011;56:7541-54.

125.Fast MF, Nill S, Bedford JL, et al. Dynamic tumor tracking using the Elekta Agility MLC: Dynamic tumor tracking using the Elekta Agility MLC. Med Phys 2014;41:111719.

126. Booth JT, Caillet V, Hardcastle N, et al. The first patient treatment of electromagnetic-guided real time adaptive radiotherapy using MLC tracking for lung SABR. Radiother Oncol 2016;121:19-25.

127. Keall PJ, Colvill E, O'Brien R, et al. The first clinical implementation of electromagnetic transponderguided MLC tracking: Clinical implementation of electromagnetic transponder-guided MLC tracking. Med Phys 2014;41:020702.

128. Tacke MB, Nill S, Krauss A, et al. Real-time tumor tracking: Automatic compensation of target motion using the Siemens 160 MLC: Real-time tumor tracking using the 160 MLC. Med Phys 2010;37:753-61.

129. Mueller M, Zolfaghari R, Briggs A, et al. The first prospective implementation of markerless lung target tracking in an experimental quality assurance procedure on a standard linear accelerator. Phys Med Biol
2020;65:025008.

130. Willoughby T, Lehmann J, Bencomo JA, et al. Quality assurance for nonradiographic radiotherapy localization and positioning systems: Report of Task Group 147: Task Group 147: Nonradiographic localization. Med Phys 2012;39:1728-47.

131.Ng JA, Booth JT, O'Brien RT, et al. Quality assurance for the clinical implementation of kilovoltage intrafraction monitoring for prostate cancer VMAT: Quality assurance for the clinical implementation of KIM. Med Phys 2014;41:111712.

132.Ipsen S, Bruder R, O'Brien R, et al. Online 4D ultrasound guidance for real-time motion compensation by MLC tracking: Online 4D ultrasound-guided MLC tracking. Med Phys 2016;43:5695-704.

133. Caillet V, Keall PJ, Colvill E, et al. MLC tracking for lung SABR reduces planning target volumes and dose to organs at risk. Radiother Oncol 2017;124:18-24.

134. Prins FM, Stemkens B, Kerkmeijer LGW, et al. Intrafraction Motion Management of Renal Cell Carcinoma With Magnetic Resonance Imaging-Guided Stereotactic Body Radiation Therapy. Pract Radiat Oncol 2019;9:e55-61.

135. Holmes JA, Zagar T, Chen R. Adoption of Stereotactic Body Radiotherapy for Stage IA Non-Small Cell Lung Cancer Across the United States. JNCI Cancer Spectrum 2017;1:pkx003.

136. Brooks ED, Ning M, Verma V, et al. Proton therapy for non-small cell lung cancer: the road ahead. Transl Lung Cancer Res 2019;8:S202-S212.

137. Gomez DR, Li H, Chang JY. Proton therapy for earlystage non-small cell lung cancer (NSCLC). Transl Lung Cancer Res 2018;7:199-204.

138. Hoppe BS, Huh S, Flampouri S, et al. Double-scattered proton-based stereotactic body radiotherapy for stage I lung cancer: a dosimetric comparison with photonbased stereotactic body radiotherapy. Radiother Oncol 2010;97:425-30.

139. Wang C, Nakayama H, Sugahara S, et al. Comparisons of dose-volume histograms for proton-beam versus 3-D conformal $x$-ray therapy in patients with stage I non-small cell lung cancer. Strahlenther Onkol 2009;185:231-4.

140.Chang JY, Zhang X, Wang X, et al. Significant reduction of normal tissue dose by proton radiotherapy compared with three-dimensional conformal or intensitymodulated radiation therapy in Stage I or Stage III nonsmall-cell lung cancer. Int J Radiat Oncol Biol Phys 2006;65:1087-96. 
141. Kadoya N, Obata Y, Kato T, et al. Dose-volume comparison of proton radiotherapy and stereotactic body radiotherapy for non-small-cell lung cancer. Int J Radiat Oncol Biol Phys 2011;79:1225-31.

142. Ebara T, Shimada H, Kawamura H, et al. Dosimetric analysis between carbon ion radiotherapy and stereotactic body radiotherapy in stage I lung cancer. Anticancer Res 2014;34:5099-104.

143. Shirai K, Kawashima M, Saitoh J, et al. Clinical outcomes using carbon-ion radiotherapy and dose-volume histogram comparison between carbon-ion radiotherapy and photon therapy for T2b-4N0M0 non-small cell lung cancer-A pilot study. PLoS One 2017;12:e0175589.

144. Georg D, Hillbrand M, Stock M, et al. Can protons improve SBRT for lung lesions? Dosimetric considerations. Radiother Oncol 2008;88:368-75.

145. Macdonald OK, Kruse JJ, Miller JM, et al. Proton beam radiotherapy versus three-dimensional conformal stereotactic body radiotherapy in primary peripheral, early-stage non-small-cell lung carcinoma: a comparative dosimetric analysis. Int J Radiat Oncol Biol Phys 2009;75:950-8.

146. Kesarwala AH, Ko CJ, Ning H, et al. Intensity-modulated proton therapy for elective nodal irradiation and involvedfield radiation in the definitive treatment of locally advanced non-small-cell lung cancer: a dosimetric study. Clin Lung Cancer 2015;16:237-244.

147. Register SP, Zhang X, Mohan R, et al. Proton stereotactic body radiation therapy for clinically challenging cases of centrally and superiorly located stage I non-small-cell lung cancer. Int J Radiat Oncol Biol Phys 2011;80:1015-22.

148. Bush DA, Cheek G, Zaheer S, et al. High-dose hypofractionated proton beam radiation therapy is safe and effective for central and peripheral early-stage non-small cell lung cancer: results of a 12-year experience at Loma Linda University Medical Center. Int J Radiat Oncol Biol Phys 2013;86:964-8.

149. Nihei K, Ogino T, Ishikura S, et al. High-dose proton beam therapy for Stage I non-small-cell lung cancer. Int J Radiat Oncol Biol Phys 2006;65:107-11.

150.Hata M, Tokuuye K, Kagei K, et al. Hypofractionated High-Dose Proton Beam Therapy for Stage I NonSmall-Cell Lung Cancer: Preliminary Results of A Phase I/II Clinical Study. Int J Radiat Oncol Biol Phys 2007;68:786-93.

151. Nakayama H, Sugahara S, Tokita M, et al. Proton Beam Therapy for Patients With Medically Inoperable Stage I Non-Small-Cell Lung Cancer at the University of
Tsukuba. Int J Radiat Oncol Biol Phys 2010;78:467-71.

152. Miyamoto T, Baba M, Sugane T, et al. Carbon ion radiotherapy for stage I non-small cell lung cancer using a regimen of four fractions during 1 week. J Thorac Oncol 2007;2:916-26.

153. Miyamoto T, Baba M, Yamamoto N, et al. Curative treatment of Stage I non-small-cell lung cancer with carbon ion beams using a hypofractionated regimen. Int J Radiat Oncol Biol Phys 2007;67:750-8.

154.Iwata H, Murakami M, Demizu Y, et al. High-dose proton therapy and carbon-ion therapy for stage I non small cell lung cancer. Cancer 2010;116:2476-85.

155. Chen J, Lu JJ, Ma N, et al. Early stage non-small cell lung cancer treated with pencil beam scanning particle therapy: retrospective analysis of early results on safety and efficacy. Radiat Oncol 2019;14:16.

156. Chi A, Chen H, Wen S, et al. Comparison of particle beam therapy and stereotactic body radiotherapy for early stage non-small cell lung cancer: A systematic review and hypothesis-generating meta-analysis. Radiother Oncol 2017;123:346-54.

157. Nantavithya C, Gomez D, Wei X, et al. Phase 2 Study of Stereotactic Body Radiation Therapy and Stereotactic Body Proton Therapy for High-Risk, Medically Inoperable, Early-Stage Non-Small Cell Lung Cancer. Int J Radiat Oncol Biol Phys 2018;101:558-63.

158. Montay-Gruel P, Petersson K, Jaccard M, et al. Irradiation in a flash: Unique sparing of memory in mice after whole brain irradiation with dose rates above 100Gy/s. Radiother Oncol 2017;124:365-9.

159.Montay-Gruel P, Acharya M, Petersson K, et al. Longterm neurocognitive benefits of FLASH radiotherapy driven by reduced reactive oxygen species. Proc Natl Acad Sci U S A 2019;116:10943-51.

160.Vozenin MC, De Fornel P, Petersson K, et al. The Advantage of FLASH Radiotherapy Confirmed in Mini-pig and Cat-cancer Patients. Clin Cancer Res 2019;25:35-42.

161. Favaudon V, Caplier L, Monceau V, et al. Ultrahigh doserate FLASH irradiation increases the differential response between normal and tumor tissue in mice. Sci Transl Med 2014;6:245ra93.

162.Lempart M, Blad B, Adrian G, et al. Modifying a clinical linear accelerator for delivery of ultra-high dose rate irradiation. Radiother Oncol 2019;139:40-5.

163. Schüler E, Trovati S, King G, et al. Experimental Platform for Ultra-high Dose Rate FLASH Irradiation of Small Animals Using a Clinical Linear Accelerator. Int J Radiat 
Oncol Biol Phys 2017;97:195-203.

164. Maxim PG, Tantawi SG, Loo BW. PHASER: A platform for clinical translation of FLASH cancer radiotherapy. Radiother Oncol 2019;139:28-33.

165. Patriarca A, Fouillade C, Auger M, et al. Experimental Set-up for FLASH Proton Irradiation of Small Animals Using a Clinical System. Int J Radiat Oncol Biol Phys 2018;102:619-26.

166.van de Water S, Safai S, Schippers J, et al. Towards FLASH proton therapy: the impact of treatment planning and machine characteristics on achievable dose rates. Acta Oncol 2019;58:1463-9.

Cite this article as: Vlaskou Badra E, Baumgartl M, Fabiano S, Jongen A, Guckenberger M. Stereotactic radiotherapy for early stage non-small cell lung cancer: current standards and ongoing research. Transl Lung Cancer Res 2021;10(4):1930-1949. doi: 10.21037/tlcr-20-860
167.Li H, Galperin-Aizenberg M, Pryma D, et al. Unsupervised machine learning of radiomic features for predicting treatment response and overall survival of early stage non-small cell lung cancer patients treated with stereotactic body radiation therapy. Radiother Oncol 2018;129:218-26.

168. Mattonen SA, Palma DA, Johnson C, et al. Detection of Local Cancer Recurrence After Stereotactic Ablative Radiation Therapy for Lung Cancer: Physician Performance Versus Radiomic Assessment. Int J Radiat Oncol Biol Phys 2016;94:1121-8. 